\title{
EDITORIAL
}

\section{DE LA MINERÍA, LA CONSULTA PÚBLICA, EL MEDIO AMBIENTE, EL DESARROLLO Y EL DERECHO}

Carlos Andrés Uribe-Piedrahita, PhD*

\section{Para citar esta editorial/To cite this editorial}

Uribe-Piedrahíta, Carlos Andrés, Editorial: De la minería, la consulta pública, el medio ambiente, el desarrollo y el derecho, 134 Vniversitas, 11-19 (2017). http://dx.doi.org/10.11144/Javeriana.vj134.mcma

doi:10.11144/Javeriana.vj134.mcma

* Profesor Investigador de la Pontificia Universidad Javeriana. Editor de la revista Vniversitas. Director de la Maestría en Derecho Económico. 
[...] es posible volver a ampliar la mirada, y la libertad humana es capaz de limitar la técnica, orientarla y colocarla al servicio de otro tipo de progreso más sano, más humano, más social, más integral.

Papa Francisco, Carta Encíclica Laudato Si'. Sobre el cuidado de la casa común

El título de este editorial es bastante largo, pero es útil proponerlo en esos términos, para que se entienda desde el principio que el punto que se presenta es poliédrico: con muchas caras y diferentes perspectivas de aproximación. La actividad extractiva en Colombia es un asunto de gran importancia, tanto para aquellos que la ven como un aliado del desarrollo económico, como para aquellos que la ven como un problema de grandes dimensiones. Estas dos visiones de la actividad extractiva representan un conjunto de desencuentros que ilustran la dificultad de definirnos como sociedad. Si sostenemos que hay un conflicto entre el soporte a la actividad minera y la búsqueda de un país libre de actividades extractivas que afectan el medio ambiente, los recursos naturales y la actividad agrícola, podemos decir que para dar una solución a estos conflictos es necesario identificar una idea de país, de desarrollo y de la regla de derecho que nos gobierna.

Uno de los grandes puntos de intersección de este debate es el alcance del principio de autonomía territorial en el marco de un Estado unitario. Como lo ha señalado la Corte Constitucional, "el principio unitario permite la existencia de parámetros generales que deben seguirse en todo el territorio nacional, mientras que el principio de autonomía territorial exige la salvaguarda de un espacio de decisión propia a las autoridades territoriales" 2 . De esta relación es natural que aparezcan conflictos, tanto por el alcance que, en el ejercicio de su competencia legal, el Congreso le otorgue

1 Papa Francisco, Carta Encíclica Laudato Si'. Sobre el cuidado de la casa común, par. 112 (Librería Editrice Vaticana, Ciudad del Vaticano, 24 de mayo de 2015). Disponible en: http://w2.vatican.va/ content/francesco/es/encyclicals/documents/papa-francesco_20150524_enciclica-laudato-si.html

2 Colombia, Corte Constitucional, Sentencia C-579-01, 5 de junio de 2001, magistrado ponente Eduardo Montealegre-Lynett. Disponible en: http://www.corteconstitucional.gov.co/relatoria/2001/c-579-01. htm Colombia, Colombia, Corte Constitucional, Sentencia C-931-06, 15 de noviembre de 2006, magistrado ponente Rodrigo Escobar-Gil. Disponible en: http://www.corteconstitucional.gov. co/relatoria/2006/c-931-06.htm. Corte Constitucional, Sentencia C-123-14, 5 de marzo de 2014, magistrado ponente Alberto Rojas-Ríos. Disponible en: http://www.corteconstitucional.gov.co/ relatoria/2014/c-123-14.htm. Colombia, Corte Constitucional, Sentencia T-445-16, 19 de agosto de 2016, magistrado ponente Jorge Iván Palacio-Palacio. Disponible en: http://www.corteconstitucional. gov.co/relatoria/2016/t-445-16.htm 
a una política de alcance nacional, como por el alcance de campos de decisión territoriales, en el marco de la Constitución y de las normas que regulan la configuración de la autonomía.

Además de estos posibles campos de conflicto por el uso de determinadas competencias legales y constitucionales, es necesario sumar su interacción con derechos superiores constitucionales que contribuyen a crear delimitaciones particulares o a extender el alcance de los balances en concreto realizados por el Congreso y en abstracto por la Constitución bajo un modelo de limitaciones recíprocas. Si bien la Corte Constitucional ha resaltado una posición de superioridad del Estado Unitario al vincular la autonomía a unos límites legales y constitucionales, tal posición queda adscrita en la práctica a una visión regulatoria de asignación de competencias, pero en la frontera de la interacción de la autonomía con otro conjunto de derechos fundamentales y colectivos, los límites de competencias se vuelven más difusos en el día a día.

Otro aspecto significativo que atraviesa este debate es la relación entre el medio ambiente y la explotación de recursos naturales no renovables. La Constitución de 1991 otorgó rango constitucional al derecho al ambiente sano, denominada en algunas oportunidades con el concepto de Constitución Ecológica ${ }^{3}$. Esta consagración tiene diferentes alcances: el ambiente como patrimonio común de la humanidad ${ }^{4}$, el ambiente como límite a los comportamientos del hombre ${ }^{5}$ y como contrapeso al desarrollo económico para la búsqueda de equilibrios ecológicos ${ }^{6}$.

Para que la idea de Constitución Ecológica tenga asidero práctico, requiere un acompañamiento y una coordinación institucional de primer nivel. Esta condición problemática en nuestro país ha sido detectada en diferentes ocasiones. Por ejemplo, el Conpes 3344 de

3 Colombia, Corte Constitucional, Sentencia T-411-92, 17 de junio de 1992, magistrado ponente Alejando Martínez-Caballero. Disponible en: http://www.corteconstitucional.gov.co/ relatoria/1992/t-411-92.htm

4 Colombia, Corte Constitucional, Sentencia C-431-00, 12 de abril de 2000, magistrado ponente Vladimiro Naranjo-Mesa. Disponible en: http://www.corteconstitucional.gov.co/relatoria/2000/c-431-00. htm

5 Colombia, Corte Constitucional, Sentencia C-671-01, 28 de junio de 2001, magistrado ponente Jaime Araújo-Rentería. Disponible en: http://www.corteconstitucional.gov.co/ RELATORIA/2001/C-671-01.htm

6 Colombia, Corte Constitucional, Sentencia T-282-12, 11 de abril de 2012, magistrado ponente Juan Carlos Henao-Pérez. Disponible en: http://www.corteconstitucional.gov.co/relatoria/2012/t-282-12. htm 
20057, el Conpes 3550 de $2008^{8}$, el Conpes 3716 de 20119 , la Política de prevención y control de la contaminación del aire, del Ministerio del Medio Ambiente, y el Informe sobre el estado de los recursos naturales y del ambiente 2015-2016, de la Contraloría General, entre otros documentos, señalan los problemas de coordinación en la implementación de políticas ambientales para el ejercicio de un desarrollo sostenible y dejan clara la existencia de desequilibrios en la planeación, implementación y verificación de las políticas que requieren del consumo de bienes renovables en relación con su protección. Bajo estas circunstancias, es necesario señalar la dificultad de la protección coherente de los intereses del Estado como sociedad, tanto en su relación con las comunidades locales, como también con los pasivos ambientales para el consumo de bienes no renovables en actividades de desarrollo económico.

En 2016, el gobierno por medio del Ministerio de Minas y Energía expidió la Política minera de Colombia, en la que señala diferentes retos prioritarios que deben ser solucionados con el fin de que esta política traslade a la sociedad sus beneficios. Entre los retos que requieren una solución eficaz están la minería ilegal e informal que afecta el medio ambiente; la inseguridad jurídica, en la cual se hace una crítica a la intervención constitucional sobre la definición de la política del Estado Unitario y la política de la autonomía en materia minera; la falta de claridad de la normativa que favorece y limita la actividad minera, en especial, por la falta de transparencia en las exclusiones ambientales; también hacen parte de esta problemática la falta de coordinación institucional ministerial, del ordenamiento ambiental y el ordenamiento departamental y municipal, esto es, problemas en la coordinación entre el Plan de Ordenación y Manejo

7 Colombia, Consejo Nacional de Política Económica y Social, Conpes 3344 de 2005, Lineamientos para la formulación de la política de prevención y control de la contaminación del aire (14 de marzo de 2005). Disponible en: http://www.minambiente.gov.co/images/normativa/conpes/2005/ Conpes_3344_2005.pdf

8 Colombia, Consejo Nacional de Política Económica y Social, Conpes 3550 de 2008, Lineamientos para la formulación de la política integral de salud ambiental con énfasis en los componentes de calidad de aire, calidad de agua y seguridad química (24 de noviembre de 2008). Disponible en: http://www.minambiente.gov.co/images/normativa/conpes/2008/Conpes_3550_2008.pdf

9 Colombia, Consejo Nacional de Política Económica y Social, Conpes 3716 de 2011, Concepto favorable a la Nación para contratar un empréstito externo con la banca multilateral hasta por US\$ 10 millones de dólares o su equivalente en otras monedas, destinados al financiamiento adicional del programa de Inversión para el Desarrollo Sostenible - IDS (2 de diciembre de 2011). Disponible en: https://colaboracion.dnp.gov.co/CDT/Conpes/Econ $\% \mathrm{C} 3 \% \mathrm{~B} 3 \mathrm{micos} / 3716 . \mathrm{pdf}$ 
de Cuencas Hidrográficas (POMCA) y los Planes de Ordenamiento Territorial (POT) de los municipios.

La Corte Constitucional ha tutelado el daño que la actividad minera ha causado al derecho de los ciudadanos a la vida, la salud, la intimidad y el ambiente $\operatorname{sano}^{10}$, y ha señalado que el cumplimiento de la normatividad no es óbice para la responsabilidad material de afectaciones a derechos superiores. En este sentido, indica la Corte en la providencia T-154-13 que:

[...] no es sustento constitucional suficiente para la continuidad, dentro de unas circunstancias que visiblemente no satisfacen la inalienable obligación “del Estado y de las personas" de proteger la riqueza natural de la Nación (artículo 8 Constitucional, no está en negrilla en el texto original), de una explotación económica, que por importante y rentable que sea no justifica el deterioro ambiental.

De esta consideración se desprende el natural límite a la libertad de empresa, a la actividad económica, a la propiedad y a la iniciativa privada por razón del bien común, el interés social y la preservación del medio ambiente. Esta idea abarca una narrativa política diferente en relación con el crecimiento económico de una sociedad, la cual busca limitar la ordenación tradicional (neoliberal) de prioridades con fundamento en un direccionamiento basado en la producción, por una medición del crecimiento que interiorice el bienestar actual y futuro de las personas ${ }^{11}$.

Entendiendo que esta valoración es correcta, también es cierto que el Estado está sujeto a responsabilidades de distinto tipo por las restricciones que genera a los derechos adquiridos, como también por los daños que causa a los particulares por ir en contra de sus propios actos, o por los daños que causa al incumplir sus compromisos con los inversionistas. Todas estas actividades del Estado comprometen recursos públicos, debido a las probables indemnizaciones que han de ser pagadas a diversos agentes económicos.

10 Colombia, Corte Constitucional, Sentencia T-154-13, 21 de marzo de 2013, magistrado ponente Nilson Pinilla-Pinilla. Disponible en: http://www.corteconstitucional.gov.co/relatoria/2013/t-154-13. htm

11 Joseph E. Stiglitz, Amartya Sen \& Jean-Paul Fitoussi, Report by the Commission on the Measurement of Economic Performance and Social Progress (2009). Disponible en: http://library.bsl.org. au/jspui/bitstream/1/1267/1/Measurement_of_economic_performance_and_social_progress.pdf 
Ante todo lo anterior, podemos señalar que el Estado tiene un deber fundamental con las sociedades actuales y futuras, un deber de crear políticas comprensivas de los diferentes intereses en juego y con carácter permanente, que tengan la suficiente coordinación institucional, tanto para el ejecutivo central como para el regional. En igual medida, es necesario encontrar una forma diferente de interactuar con la Corte Constitucional, pues la percepción actual es la de un nivel de intervención regulatoria que no facilita el avance de las diferentes políticas públicas, tanto para el medio ambiente como para desarrollo de la actividad minera.

El 26 de marzo de 2017 se realizó la consulta popular en el municipio de Cajamarca, departamento del Tolima, donde se preguntó a la población: ¿Está usted de acuerdo Sí o No que en el municipio de Cajamarca se ejecuten proyectos y actividades mineras? El resultado de la votación fue casi del $98 \%$ a favor del No (6.195 votos a favor del No y 76 a favor del Sí). Hubo una participación de 6.241 votos válidos que constituían casi el $36 \%$ de los 16.312 votantes del censo electoral. A partir de este fenómeno de participación ciudadana, surgen cuestionamientos muy importantes para diferentes actividades económicas en el país. Sin demeritar en ningún sentido la participación de los ciudadanos, es necesario reflexionar sobre el alcance de las políticas públicas de nivel nacional, pues si se admite que el sector minero-energético representa alrededor del 7\% del PIB, del cual la minería es el 2,1\% y aporta ingentes recursos al desarrollo por medio de las regalías, el empleo y la compra de productos y servicios: ¿cómo piensa el gobierno planear una política pública de impacto nacional que pueda ser decidida o limitada mediante consultas populares locales? También se debe preguntar si la consulta limita, en algún grado, la titularidad efectiva del subsuelo. Esta pregunta parte de la base de que la consulta popular podría entenderse como la asignación (para efectos prácticos) de una regla de exclusión a favor de un municipio a la posibilidad de proyectos mineros planeados por la política nacional minera.

No se debe entender que en estas líneas haya alguna propensión por sacrificar el medio ambiente a favor de la explotación de recursos no renovables; lo que se plantea de manera directa es la imperiosa necesidad de una planeación minera que permita conocer el grado de equilibrio que se considera apropiado entre el 
consumo de bienes no renovables y la explotación económica de los recursos no renovables. Pues, en definitiva, el incumplimiento de las obligaciones que asume el Estado con los particulares que deciden invertir recursos financieros en la explotación de recursos no renovables y posteriormente son limitados o excluidos de sus actividades bajo regulaciones ex post o intervenciones ad hoc, terminará, con gran probabilidad, en indemnizaciones. Así, es un deber del Estado la creación de políticas públicas que minimicen los costos de incertidumbre e incumplimiento, para dar el balance ex ante necesario en la protección de los intereses de mayor valor que permitan un crecimiento económico sostenible y coherente con las necesidades económicas, el bien común, el interés social y la preservación del medio ambiente. 


\section{BIBLIOGRAFÍA}

\section{Normatividad colombiana}

Colombia, Consejo Nacional de Política Económica y Social, Conpes 3344 de 2005, Lineamientos para la formulación de la política de prevención y control de la contaminación del aire (14 de marzo de 2005). Disponible en: http://www. minambiente.gov.co/images/normativa/conpes/2005/Conpes_3344_2005.pdf

Colombia, Consejo Nacional de Política Económica y Social, Conpes 3550 de 2008, Lineamientos para la formulación de la política integral de salud ambiental con énfasis en los componentes de calidad de aire, calidad de agua y seguridad química (24 de noviembre de 2008). Disponible en: http://www.minambiente. gov.co/images/normativa/conpes/2008/Conpes_3550_2008.pdf

Colombia, Consejo Nacional de Política Económica y Social, Conpes 3716 de 2011, Concepto favorable a la Nación para contratar un empréstito externo con la banca multilateral hasta por US\$ 10 millones de dólares o su equivalente en otras monedas, destinados al financiamiento adicional del programa de Inversión para el Desarrollo Sostenible - IDS (2 de diciembre de 2011). Disponible en: https:// colaboracion.dnp.gov.co/CDT/Conpes/Econ $\% \mathrm{C} 3 \% \mathrm{~B} 3 \mathrm{micos} / 3716 . \mathrm{pdf}$

\section{Jurisprudencia colombiana}

Colombia, Corte Constitucional, Sentencia C-431-00, 12 de abril de 2000, magistrado ponente Vladimiro Naranjo-Mesa. Disponible en: http://www. corteconstitucional.gov.co/relatoria/2000/c-431-00.htm

Colombia, Corte Constitucional, Sentencia C-579-01, 5 de junio de 2001, magistrado ponente Eduardo Montealegre-Lynett. Disponible en: http://www. corteconstitucional.gov.co/relatoria/2001/c-579-01.htm

Colombia, Corte Constitucional, Sentencia C-671-01, 28 de junio de 2001, magistrado ponente Jaime Araújo-Rentería. Disponible en: http://www.corteconstitucional. gov.co/RELATORIA/2001/C-671-01.htm

Colombia, Corte Constitucional, Sentencia C-931-06, 15 de noviembre de 2006, magistrado ponente Rodrigo Escobar-Gil. Disponible en: http://www. corteconstitucional.gov.co/relatoria/2006/c-931-06.htm

Colombia, Corte Constitucional, Sentencia C-123-14, 5 de marzo de 2014, magistrado ponente Alberto Rojas-Ríos. Disponible en: http://www.corteconstitucional. gov.co/relatoria/2014/c-123-14.htm

Colombia, Corte Constitucional, Sentencia T-411-92, 17 de junio de 1992, magistrado ponente Alejando Martínez-Caballero. Disponible en: http://www. corteconstitucional.gov.co/relatoria/1992/t-411-92.htm

Colombia, Corte Constitucional, Sentencia T-282-12, 11 de abril de 2012, magistrado ponente Juan Carlos Henao-Pérez. Disponible en: http://www.corteconstitucional. gov.co/relatoria/2012/t-282-12.htm 
Colombia, Corte Constitucional, Sentencia T-154-13, 21 de marzo de 2013, magistrado ponente Nilson Pinilla-Pinilla. Disponible en: http://www.corteconstitucional. gov.co/relatoria/2013/t-154-13.htm

Colombia, Corte Constitucional, Sentencia T-445-16, 19 de agosto de 2016, magistrado ponente Jorge Iván Palacio-Palacio. Disponible en: http://www. corteconstitucional.gov.co/relatoria/2016/t-445-16.htm

\section{Documentos, informes, reportes}

Colombia, Contraloría General de la República, Informe sobre el estado de los Recursos Naturales y del Ambiente 2015-2016 (Contraloría General de la República, Bogotá, 2016). Disponible en: http://www.contraloria.gov.co/documents/20181/461292 / Informe + sobre +el+Estado $+\mathrm{de}+1 \mathrm{os}+\mathrm{Recursos}+\mathrm{Naturales}+\mathrm{y}+$ del+Ambiente+2015+-+2016/b89427cb-857e-407c-9ef3-1aac6aaf3708?version=1.1

Colombia, Ministerio de Ambiente, Vivienda y Desarrollo Territorial, Política de Prevención y Control de la Contaminación del Aire (Ministerio de Ambiente, Vivienda y Desarrollo Territorial, Bogotá, 2010). Disponible en: http:// www.minambiente.gov.co/images/AsuntosambientalesySectorialyUrbana/ pdf/Polit $\%$ C3\%ACcas_de_la_Direcci\%C3\%B3n/Pol\%C3\%ADtica_de_ Prevenci $\%$ C3\%B3n_y_Control_de_la_Contaminaci $\% \mathrm{C} 3 \% \mathrm{~B} 3 \mathrm{n}$ _del_Aire.pdf

Colombia, Ministerio de Minas y Energía, Política Minera de Colombia. Bases para la minería del futuro (Ministerio de Minas y Energía, Bogotá, 2016). Disponible en: https://www.minminas.gov.co/documents/10180/698204/Pol\%C3\%ADtica+Min era+de+Colombia+final.pdf/c7b3fcad-76da-41ca-8b11-2b82c0671320

PAPA Francisco, Carta Encíclica Laudato Si'. Sobre el cuidado de la casa común (Librería Editrice Vaticana, Ciudad del Vaticano, 24 de mayo de 2015). Disponible en: http://w2.vatican.va/content/francesco/es/encyclicals/documents/papafrancesco_20150524_enciclica-laudato-si.html

Stiglitz, Joseph E.; Sen, Amartya \& Fitoussi, Jean-Paul, Report by the Commission on the Measurement of Economic Performance and Social Progress (2009). Disponible en: http://library.bsl.org.au/jspui/bitstream/1/1267/1/Measurement_ of_economic_performance_and_social_progress.pdf 
